\title{
The place of subfascial endoscopic perforator vein surgery (SEPS) in advanced chronic venous insufficiency treatment
}

\author{
Wiesław Pesta ${ }^{1}$, Waldemar Kurpiewski ${ }^{1}$, Marek Kowalczyk ${ }^{1}$, Rafał Szynkarczuk ${ }^{1}$, Magdalena Łuba $^{1}$, Anna Żurada ${ }^{2}$, \\ Radosław Grabysa ${ }^{3}$ \\ 1Department of General and Minimally Invasive Surgery, University Hospital and Clinics, Olsztyn, Poland \\ 2Department of Anatomy, University of Warmia and Mazury, Olsztyn, Poland \\ ${ }^{3}$ Department of Internal Diseases, Gastroenterology and Hepatology, University Hospital, Olsztyn, Poland
}

Videosurgery and Other Miniinvasive Techniques 2011; 6 (4): 181-189 DOI: $10.5114 /$ wiitm.2011.26252

\begin{abstract}
In spite of medical science development and initiation of new technologies in minimally invasive surgery, treatment of advanced chronic venous insufficiency at the $5^{\text {th }}$ and $6^{\text {th }}$ degree of CEAP classification is still a great clinical challenge. In case of no satisfactory results of non-surgical treatment of recurrent venous ulcers, scientists search for alternative therapeutic methods which could be more effective and lasting. Subfascial endoscopic perforator vein surgery (SEPS) as a method of reducing venous pressure in the superficial venous system could provide healing of the recurrent venous ulcer. In this study we present a review of contemporary opinions about the place and significance of subfascial endoscopic perforator vein surgery as a treatment of advanced chronic venous insufficiency.
\end{abstract}

Key words: cruroscopy, subfascial endoscopic perforator surgery, chronic venous insufficiency, perforating veins, leg venous ulcer.

\section{Introduction}

A lower leg ulcer, having catastrophic consequences, is the most cost-generating complication in phlebology. Economy, time and effort spent and, last but not least, the quality of patients' life are the factors to be considered. Progress in understanding the causes of the complication which we are all afraid of - uncontrolled venous hypertension - as well as careful assessment of treatment modalities and their results has made it possible to develop rational and scientifically based guidelines. In this regard the crucial question is not how to cure ulcer, but how to prevent its recurrence. This presents a real challenge as for many various reasons surgical correction of venous hypertension is often impossible, and its treatment should be based on acceptable and effective external methods of decreasing it. The role of pharmacotherapy in venous ulcer treatment has not been entirely determined yet [1]. Surgical ablation of the incompetent superficial venous system performed to decrease pressure has been the basic procedure in treatment of chronic tibial ulcers for almost 100 years [2]. It concerns the saphenous vein, small saphenous vein, their inflows and perforating veins. Incompetent perforating veins (ICPV) constitute an especially important aetiological factor in tibial chronic venous ulcer pathogenesis. Subfascial endoscopic perforator surgery (SEPS) or, used in German literature, Die endoscopische subfasciale Dissektion Perforansvenen (ESDP), since 2004 Endoscopische 
Perforantensanierung (EPS), is the basic method recommended for the reduction of incompetent superficial venous system pressure and tibial ulcer treatment [2-5].

The validity of such proceedings has been supported by many clinical trials performed within evidence-based medicine (EBM), which facilitates the choice of the optimal treatment on the basis of the newest, available data. It also enables statistical power analysis and credibility assessment of trials which test the effectiveness of a particular method $[6,7]$.

\section{Definition and epidemiology}

In the literature, chronic venous disease (CVD) is synonymous with chronic venous insufficiency (CVI) and refers to the physiological outcomes of deep venous flow disorder, valve insufficiency or both disorders combined. Post-phlebitic or post-thrombotic are, on the other hand, used to describe pathological and clinical aspects of venous insufficiency resulting from deep vein thrombosis. One of the modern, prospective studies revealed that features of venous insufficiency are observed in $80 \%$ of patients within 5 years following deep venous thrombosis. The incidence of chronic venous disease is estimated at $0.5-3 \%$ of the adult population in Europe and Ameri$\mathrm{ca}$ [8]. The prevalence of venous insufficiency increases with age, up to 3 times in patients over 50. Considering all the other factors, men have 1.5 times higher probability of venous reflux than childless women, and increased familial incidence is noted, while in female patients the incidence increases with the number of pregnancies. The USG results showed that in 1 out of 5 young people, regardless of sex, some degree of venous reflux intensification is observed. Cutaneous signs of chronic venous insufficiency are noted in $20 \%$ of patients, severe changes in $9 \%$ and ulcer in 1.3\% [9]. In the European countries the costs of chronic venous disease management range from $1.5 \%$ to $2 \%$ of the whole medical expenditure. Assessment of quality of life of patients with venous diseases has become the goal of epidemiologists' work. It is clearly dependent on CVI [10].

\section{Anatomy of perforating veins}

Detailed knowledge of the lower limbs venous penetrating system is essential for both differential diagnostics and treatment of venous diseases. Veins differ from arteries in terms of wall structure, blood flow conditions and internal pressure. It leads to significant alteration in endothelial function and blood coagulation. A surgeon handling venous diseases must be aware of this. Veins are web-like blood vessels, and blood is collected into bigger and bigger vessels. Unlike arterial branches, veins have tributaries. The venous system of the limbs may be divided into epi - and subfascial due to the presence of fascia. Both systems are connected with about 150 penetrating veins which create a web-like structure. Deep veins play the most important role in blood outflow from the limbs. Superficial and perforating veins are subsidiary. Lower limb muscles play a crucial role in creating a peripheral venous pump. Perforator veins connect superficial and deep veins penetrating the muscular fascia. They are guarded with valves which facilitate the blood flow from the superficial to the deep circulation. During the 1979 congress, the name "connecting veins" was proposed for lateral veins constituting connections within one circulation: superficial or deep. The name "penetrating veins" was suggested for all the veins interconnecting both circulations $[5,10]$. Perforating veins possess valves whose closure prevents the backward flow of the blood. They consist of 2, and sometimes 3 folds with edges pointing in the direction of the lumen of the vessel. Just next to the valve, the venous wall is usually dilated into a sinusoidal bulge.

The valve is usually located below the orifice of the venous tributary, and the lumen of the vein is usually wider above, not below the valve. Such morphological presentation is described as telescopic Hach's symptom. It has a huge diagnostic value of venous flow [5]. Sometimes before crossing the fascia, perforating veins form a small, s-shaped loop. It prevents light refraction and excessive vein stretching, when the skin and tissue move along the fascia. Valveless, perforating veins with bidirectional blood flow were also described [10]. According to Linton, the normal perforating vein diameter may vary from $1 \mathrm{~mm}$ to $2 \mathrm{~mm}$ [11]. Mozes observed that only $1 / 4$ of normal perforating veins have a diameter exceeding 2 mm [10]. In 1867 Le Dentu introduced a division, classic today, of perforating veins into direct and indirect. Others believe that such division was made several dozen years later by Warwick [10]. Direct perforating veins connect big, superficial veins - the saphenous vein, small saphenous vein and their collateral branches - with major deep veins. They are 
short, transverse, sometimes slightly rising or falling when crossing the fascia. These large diameter veins show a relatively constant anatomical distribution. Cockett and Jones proved that they play the main pathophysiological role in the so-called post-thrombotic syndrome [12]. Indirect perforator veins, on the other hand, have a small diameter and are large in number. They are characterized by a meander-like flow and ramifications at either one end or along their whole length. They communicate deep veins with superficial veins via one or more intramuscular veins. Dodd and Cockett showed that the perforator veins do not play any significant role in CVI pathology [13]. Due to diversity of appearance it is impossible to describe precisely all perforating veins' topography. Regarding the CVD, Cockett's veins are the most significant. Their incompetence is connected with varied clinical presentations. These should be treated as a direct cause of both $\mathrm{CVI}$ and all the complications arising from the condition including arthrogenic congestive syndrome and chronic syndrome of intrafascial tibial hypertension. Less frequently, Cockett's perforators' insufficiency is an autonomic clinical presentation [11]. Three sets of Cockett's perforators, located in the interior part of the distal tibia, have been identified the upper, middle and lower. They connect the posterior arch vein with the posterior tibial veins.

At times, a perforator comes out directly from the saphenous vein. The characteristic cutaneous projection of crural fascia diminution agrees with so-called virtual Hach's positional lines [11]. The lower Cockett's perforator is located near the medial malleolus, while the middle Cockett's perforator is a general idea, which includes 3 sets of vessels: anterior, medial and posterior. Their identification, which is related to muscular septum topography, may be performed clinically and intraoperatively, but it is not possible during USG or phlebological examination. The anterior vessel is located directly on the periosteum of the posterior part of the tibial bone. The medial vein runs next to the intramuscular septum. The topography of the upper Crockett's veins shows similar characteristics, but it lacks the posterior vessel. Typical incompetent perforating veins of the lower limb are presented in Figure 1.

\section{Pathogenesis and pathophysiology}

Perforating veins of the lower extremities are anatomically heterogeneously located, but not all of them become insufficient. The ultrasonic criteria of perforating vein incompetence play a crucial role not only in determining whether the intervention limited to the saphenous vein will eliminate the perforators' insufficiency, but most of all in determining whether the perforating vein is really incompetent, before engaging in any kind of surgical treatment. In the literature there is no standard diagnostic parameter allowing perforating vein insufficiency duplex scan determination [14]. Reflux is an ultrasonic symptom of the perforator's incompetence. Shin ultrasonography (USG) examination should be performed in a sitting patient with the leg lowered. It is sometimes possible to observe vaguely visible, retrograde to the outside blood flow during phlebography. If, however, all the other criteria of the perforator's competence are met, this symptom cannot be treated as an indication of vessel insufficiency. Only the occurrence of regular blood flow inversion influences the morphology of the vessel [11]. In most clinical trials, criteria for perforating vein insufficiency consist of reflux persisting for longer than $0.5 \mathrm{~s}$ taken while pressure is applied to the calf. In some other trials the diameter of the perforator is assessed as an additional criterion. In his studies, Yamamoto took into account both parameters [15]. It was observed that insufficient perforating veins had $3.59 \mathrm{~mm}$ diameter $\pm 0.94 \mathrm{~mm}$ and competent perforators $2.61 \pm 0.91 \mathrm{~mm}$. The difference amounted to about $1 \mathrm{~mm}$. Finally, it was observed that reflux persistence sensitivity was insufficient in the assessment of perforating vein competence. On the basis of these trials' analysis it can be acknowledged that if the diagnostic criteria are strict, fewer perforators are classified as incompetent; if they are either more liberal or a few parameters are used, more are classified as incompetent. The most significant cause of lower limbs' chronic venous insufficiency is deep venous valvular insufficiency [15]. In most cases, it develops after deep vein thrombosis when the majority of veins undergo partial or full recanalization [16]. As a result of ongoing phlebitis, delicate folds of the valve become thicker, shorter and pulled into the cicatricial tissue of the venous wall, which makes them unable to provide the right blood flow and prevent reversed blood flow. The vein renders an unyielding, thick-walled pipe with the remains of incompetent valves and connective tissue adhesions stretched out in its lumen. Secondary valvular insufficiency occurs in the areas distal to chronic flow disorders or significant reflux. High pres- 
A

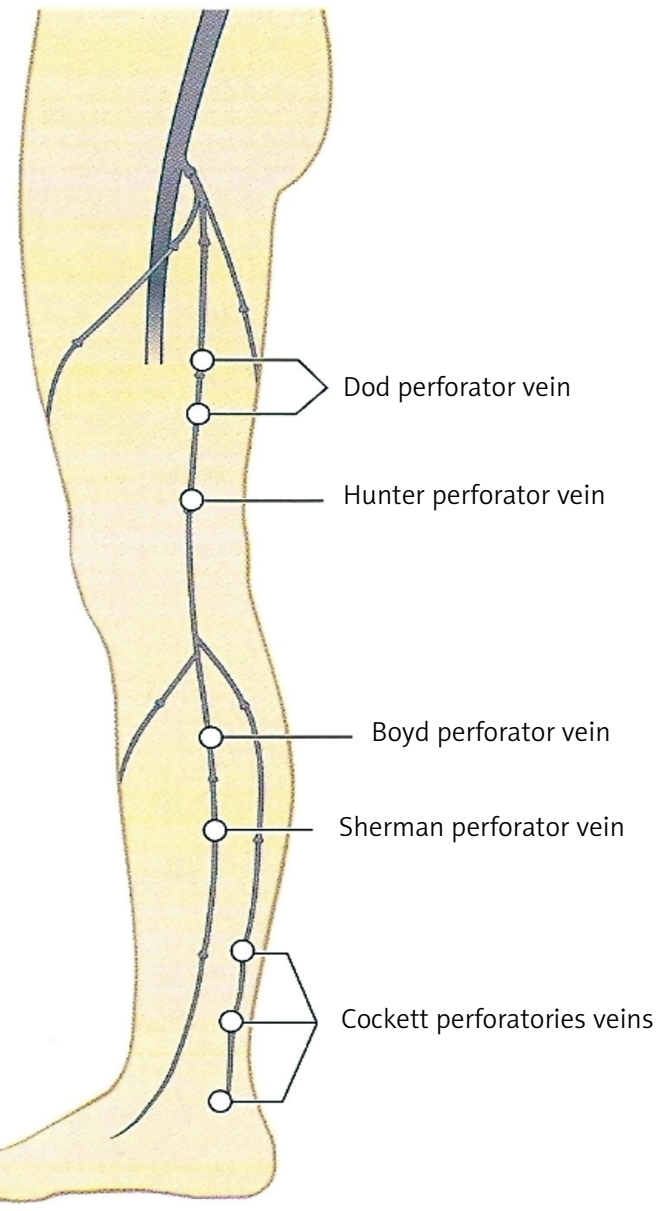

B

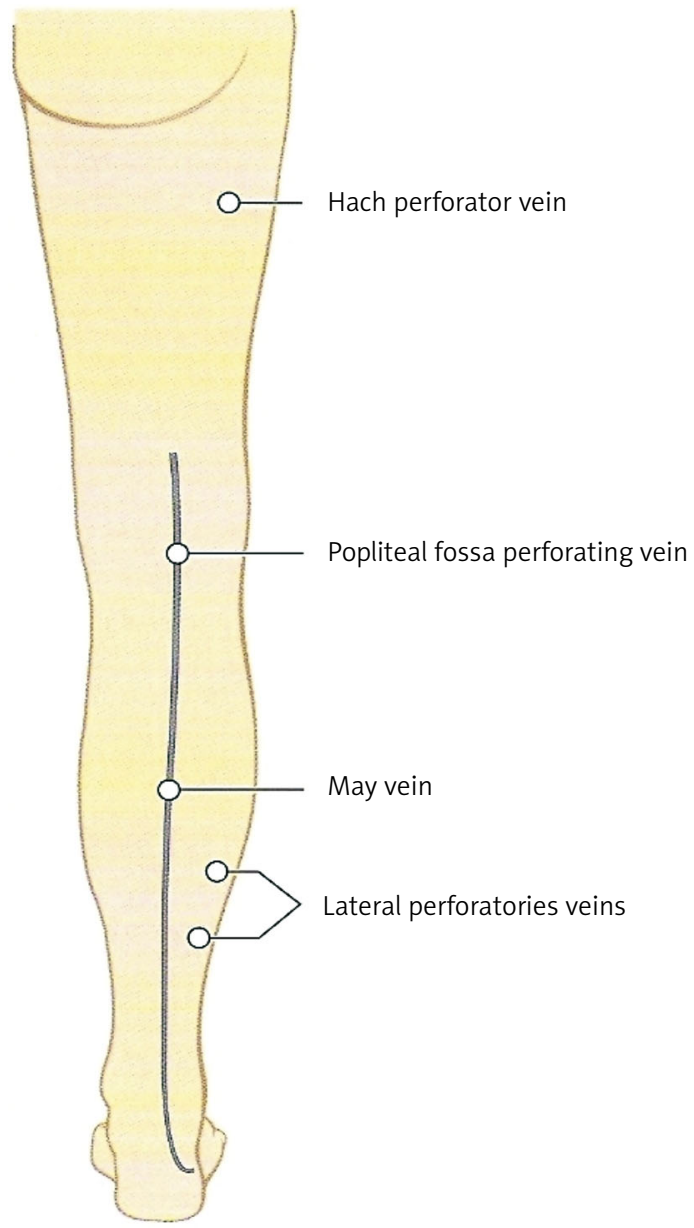

Figure 1. The schematic of the most important: A) on the medial side, B) behind the limp [10]

sure widens the veins, causing leaflets to lengthen and divide, which results in the subsequent leak. Frail valve construction with the perforating folds may occur as a primary ailment, with no previous deep vein thrombosis $[17,18]$.

In case of valvular insufficiency the blood flow and the evacuation of blood from the deep veins are disturbed. With the muscle pump activation, blood flow in the leg may be partially reversed. It is connected with valve damage. Increased flow in the secondary venous connections, superficial vein congestion and valvular insufficiency occur, exposing subcutaneous tissue to high pressure, especially during muscle contraction $[19,20]$. The number of capillary vessels with an abnormal level of fibrinogen in the subcutaneous tissue and fibrin in the interstitial space increases. Macrophage and other inflammatory vessel infiltration leading to capillary fibrosis occur, which presents with thickening and hardening of subcutaneous tissue. Brown skin pigmentation results from deposition of larger amounts of hemosiderin from erythrocyte decomposition. Repeated episodes of barotrauma and persistent capillary hypertension, interstitial oedema and inflammation cause local oxygen deficiency and malfunctioned tissue nutrition. Necrosis and subcutaneous tissue hardening appear followed by cutaneous lesions with ulcer. At this point, secondary bacterial colonization and connective tissue inflammation may take place, which results in considerable disease flare [21].

\section{Diagnostics}

Lesions in deep veins and concomitant middle and upper Cockett's penetrating veins are responsible for the clinical presentation of chronic venous 
insufficiency [5]. The CVI related chronic cutaneous lesions located above the medial malleolus with dynamic venous hypertension are a reliable indication of Cockett's perforators' insufficiency. Cockett's perforating veins' insufficiency related CVI with competent deep veins does not occur in clinical presentation [5]. In a limb examination a blowout appears over the incompetent perforating vein. In the literature, it is referred to as a Dow's sign [5]. In the clinical picture of examined limb phlebectasia, abnormal pigmentation, tissue hardening, cicatrization, eczema and, in the most advanced cases, ulcer of varying severity frequently appear [5]. Physical examination should include palpation and tapping of the varices and main superficial venous trunks, classic varicose tests such as cough impulse test over the saphenous vein opening, Schwartz test and tourniquet tests. The Trendelenburg, Chevrier and Perthes tests are especially useful in the diagnosis of tibial perforating veins' insufficiency. A murmur or vibration may denote an arteriovenous fistula. It is also necessary to remember to take the pulse rate in the common areas of the lower extremities [10]. The classification of the disease is crucial for uniform diagnosis of CVI and scientific data exchange. Until recently, too much pressure was put on external symptoms of chronic venous insufficiency such as varices, cutaneous changes and ulcer, with no objective examination of the venous system being performed in order to confirm the diagnosis. Such practice may be the cause of diagnostic mistakes and is mostly responsible for poor treatment and therapeutic modalities correlation results. In 1994 the American Venous Forum created a CVI classification including the clinical presentation, aetiology, anatomical range and pathomechanism, which was a step forward (CEAP classification) (Table I). This action constituted the basis of objective diagnostics [22]. The CEAP classification was spread all over the world. The updated CEAP classification should be used, according to which patients are assigned to one of the 7 clinical groups (C 0-6), depending on signs and symptoms severity. Before treatment and after its discontinuation, every patient should be included in the appropriate CEAP group. A lower class after treatment means clinical improvement. The Ad Hoc Committee of the American Venous Forum on Chronic Venous Disease proposed a clinical severity score including the assessment of pain, oedema, venous claudication, skin discoloration, lipodermatosclerosis and the size, amount, duration and recurrence rate of ulcer. Every parameter is assessed on a scale of 0-2. It allows evaluation of lesions prior to and after surgical treatment. It is also suggested that the CEAP classification could be used to assess a patient's incapacity before treatment and after it is discontinued. Physical effects and patient's ability to work are shown as points [22]. In patients operated on due to isolated superficial venous insufficiency, clinical assessment according to the CEAP classification is enough at times. In the case of more advanced CVD, additional examinations can be used in order to assess the results of treatment. The objective evaluation is necessary in patients with no improvement or with recurrent symptoms and in patients enrolled in clinical trials. Clinical investigation only is not sufficient for precise location of incompetent Cockett's perforators despite typical clinical features of this pathology. Additional imaging is necessary in the preoperative period [10]. Duplex examination is the test of choice for verification of reflux remission in superficial and perforating veins, while for quantitative evaluation of haemodynamic changes it is pneumatic plethysmography or foot volumetry [10, 22].

In ascending phlebology, incompetent perforators can be easily identified as long as they are clinically, haemodynamically significant [10]. Colour Duplex Doppler ultrasound is one of the routine diagnostic modalities of perforators. It is conducted in patients in a sitting position with the limb lowered. The distal compression test is useful in determining reversed or oscillating blood flow and valvular insufficiency. It is possible to identify in the USG the change of a perforator's course from atilt to transverse and vessel widening. On the basis of intraoperative USG test results verification and evaluation made during the procedure performed in the epifascial space, the efficiency of USG diagnostics was estimated at $95 \%$. Phlebographic sensitivity was only $70 \%$ [5].

\section{Surgical treatment}

Conservative therapy modalities do not allow durable closure of the vascular lumen. Surgical management is the treatment of choice due to intrafascial connection of incompetent Cockett's perforators with the deep venous system, large volume of reversed blood and high flow speed [2, 3, 5-7]. Ligature of perforating veins, since the first procedure described by Gay in 1868, has been performed by 
Table I. CEAP classification

\begin{tabular}{|c|c|c|}
\hline \multicolumn{3}{|c|}{ CEAP classification } \\
\hline C & \multicolumn{2}{|c|}{$\begin{array}{l}\text { Clinical severity (class 0-6), with a letter A in patients with no symptoms (asymptomatic) and letter S in patients with } \\
\text { symptoms (symptomatic) }\end{array}$} \\
\hline E & \multicolumn{2}{|l|}{ Aetiology or cause (congenital, primary, secondary) } \\
\hline A & \multicolumn{2}{|c|}{ Anatomy (superficial, deep or perforating, isolated or combined) } \\
\hline$P$ & \multicolumn{2}{|c|}{ Pathophysiology (reflux and obstruction, isolated or combined) } \\
\hline \multicolumn{2}{|c|}{ Classification (P) } & Anatomy $(A)$ \\
\hline PR & Reflux & As Superficial veins \\
\hline PO & Obstruction & 1. Telangiectasias or reticular veins \\
\hline PN & No venous pathophysiology & 2. Great saphenous vein above knee \\
\hline \multicolumn{2}{|c|}{ Clinical classification (C) } & 3. Great saphenous vein below knee \\
\hline \multirow[t]{2}{*}{$\mathrm{CO}$} & \multirow{2}{*}{$\begin{array}{l}\text { No visible or palpable signs of venous circulation } \\
\text { pathology }\end{array}$} & 4. Small saphenous vein \\
\hline & & 5. Non-saphenous veins \\
\hline C 1 & Telangiectasias or reticular veins & Ad Deep veins \\
\hline C 2 & Varicose veins $>3 \mathrm{~mm}$ & 6. Inferior vena cava \\
\hline C 3 & Oedema & 7. Common iliac vein \\
\hline \multirow[t]{3}{*}{ C 4} & $\begin{array}{l}\text { Changes in skin and subcutaneous tissue secondary to } \\
\text { CVD }\end{array}$ & 8. Internal iliac vein \\
\hline & C $4 a$ - pigmentation or eczema & 9. External iliac vein \\
\hline & C 4b-Ipodermatosclerosis or atrophie blanche & 10. Pelvic: gonadal, broad ligament veins, other \\
\hline C 5 & Cutaneous changes as above with healed venous ulcer & 11. Common femoral vein \\
\hline C 6 & Cutaneous changes as above with active venous ulcer & 12. Deep femoral vein \\
\hline \multicolumn{2}{|c|}{ Aetiological classification (E) } & 13. Femoral vein \\
\hline Ec & Congenital & 14. Popliteal vein \\
\hline Ep & Primary, no cause identified & $\begin{array}{l}\text { 15. Crural: anterior tibial, posterior tibial, peroneal veins } \\
\text { (all paired) }\end{array}$ \\
\hline \multirow[t]{4}{*}{ Es } & Secondary, cause identified & 16. Muscular: gastrocnemial, soleal veins, other \\
\hline & Post-thrombotic & Ap Perforating veins \\
\hline & Post-traumatic & 17. Thigh \\
\hline & Other & 18. Calf \\
\hline En & No venous cause identified & An No venous pathophysiology identifiable \\
\hline
\end{tabular}

many surgeons. Many others have been discouraged to use it in ulcer treatment due to technical difficulty in finding and excising veins in subcutaneous tissue hardened because of lipodermatosclerosis. Linton and Boston made significant progress in 1938. They described a procedure of subfascial ligation of incompetent perforators. In 1953 Cockett and Elgin Jones performed detailed autopsy examination in order to 
locate precisely shank and crurotalar joint perforating veins. Harold Dodd proposed a modification of Linton's procedure in 1964. He showed that improvement of wound healing could be achieved by making a cutaneous incision for subfascial ligation via a posterior-medial approach instead of a medial approach within the zone of skin adipose hardening. The authors have took keen interest in perforating vein ligation as a means of venous ulcer management, which between 1961 and 1971 resulted in numerous, conscientiously documented clinical trials concerning the effects of such treatment [1]. A few technical modifications of surgical treatment were introduced in order to minimize the percentage of complications connected with subfascial ligation of perforators such as cutaneous incision remote from the ulcer, in the posterior area of the lower leg, the so-called posterior stocking seam approach [23]. Hauer modified available endoscopic techniques in order to ligate incompetent perforating veins by making an incision in the proximal medial area of the lower limb using mediastinoscopy and vascular clips [24]. In 1991 O'Donell introduced a technique with an endoscopic approach, for which he used microinstruments and a video channel for the first time $[25,26]$. Gloviczki and Conrad modified, independently from each other, the endoscopic method by the use of a tourniquet and $\mathrm{CO}_{2}$ insufflation, which improved visualization of the subfascial space and allowed one to unveil, clip and incise incompetent perforating veins precisely [27-29]. In Poland SEPS was introduced in 1989 when a typical endoscopic kit for the Hauer technique was used. Later on, the technique was improved by the introduction of video channelling and manipulators used in laparoscopic kits and also by $\mathrm{CO}_{2}$ subfascial insufflation [27, 30-35]. The present authors began to employ SEPS technique in advanced CVD treatment in 1999 with the equipment used in laparoscopy with $10 \mathrm{~mm}$ simple optics, two $10 \mathrm{~mm}$ trocars and $\mathrm{CO}_{2}$ insufflation performed at maximum $15 \mathrm{mmHg}$ for better exposure of the subfascial space. At first, incompetent Cockett's perforators were closed with titanium clips, and from 2004 they were cut directly with harmonic scissors, interchangeably with Ligasure forceps. Our own modification prepared on the basis of a few years' experience [30] allowed for the decrease of intraoperative bloody complications connected with damaged perforators, and also influenced the amount of paresthesias over the medial malleolus.

\section{Discussion}

The analysis of the available literature forms the basis for the statement that endoscopic, subfascial incision of incompetent perforating veins in the case of advanced chronic disease is a suitable therapeutic choice taking into account the complex pathogenesis of this disease [4, 9, 10, 22, 24, 26-30, 32-39]. The relatively simple endoscopic technique combined with proximal saphenectomy and traditional varicose surgery appears to be a successful method of combating the effects of hypertension in the lower extremities that is possible to popularize - contrary to technically challenging surgery of the venous system such as valvuloplasty, transposition, vein valve transplantation, or valve formation $[9,30]$. In the global literature a series of data supporting surgical procedures can be found relating to superficial and perforating veins, especially in patients classified as groups 5 and 6 according to CEAP. Most authors believe that medicine based on facts should be the basis of therapeutic management choice. For the proper evaluation of therapeutic measures it is necessary to determine the final goal of treatment. In other words, it is necessary to formulate the same final points for each study. In our study the influence of incompetent perforating vein treatment on ulcer healing and its recurrence, and the influence of selective treatment of the saphenous vein on the same output points were taken into account. Studies assessing the length of life with no recurrence and the quality of life were also analysed. Until the end of 2002 no randomized study assessing ulcer healing or its recurrence was published [40], and by the end of 2007, four studies meeting the inclusion criteria had appeared in the literature: two at the first credibility level, and two at the second credibility level [41-44]. Among data included in those studies, the conclusions arising from van Gent's observations from 2006 are especially interesting [43]. In 170 patients with C6 changes according to CEAP, 200 extremities were treated. The patients were divided into two groups. One series underwent compression therapy; in the other compression therapy combined with SEPS with or without saphenous vein cut-down was employed. The evaluation of endoscopic subfascial cut-down of incompetent perforators' influence on ulcer healing and recurrence was the most important issue. Twenty centres participated in the study and the length of life without recurrence was the main endpoint. Ulcer healing, ulcer recurrence, quality of 
life and profitability analysis were the secondary endpoints. Simultaneously, in $54 \%$ the procedure was performed within either the saphenous vein or the small saphenous vein. In 40 patients saphenectomy or parvectomy was previously carried out. Only in $6 \%$ of patients were perforating veins solely treated. In consequence there is no possibility of saphenous vein and perforator treatment differentiation. After the observation period (27 months on average) survival with no recurrence was $72 \%$ in the series surgically treated in comparison to $53 \%$ in the group with compression therapy employed. Similar values were observed in the case of ulcer recurrence and healing. After stratification of the assessed results, it turned out that recurring ulcer and surgical treatment in the specialized centre favoured longer life without recurrence and deep venous reflux was not influential. As mentioned before, the most significant indicator of endoscopic subfascial incompetent perforator cutdown effectiveness is the speed and effectiveness of venous ulcer healing. In Ciostek's material, $43 \%$ of ulcers healed within a month and $92 \%$ within 6 months after the surgery [9]. Gloviczki, in his work, describes a slightly slower healing process after SEPS [45]: $15 \%$ after 30 days, $67 \%$ after 90 days and $79 \%$ after 180 days. Jugenheimer, on the other hand, reports a $94 \%$ rate of ulcer healing [46]. The lower percentage of ulcer healing may, according to different authors [37, 47], result from the lack of radicalness in identification and endoscopic provision of incompetent Cockett's perforating veins, especially the lowest ones, due to technically difficult accessibility. Despite that, the final results of the advanced chronic disease are promising when taking into account the most significant treatment parameters. They are, however, the best when compression therapy is combined with subfascial perforating vein cut-down complemented by simultaneous or proximal stripping of the saphenous vein and sometimes, especially in the case of vast, circular leg ulcers, by autogenic, meshy cutaneous transplant [30].

\section{Conclusions}

1. Cruroscopy with SEPS/ESDP is an effective and safe method of treatment of advanced, chronic venous disease of lower extremities.

2. The use of laparoscopic optics and subfascial $\mathrm{CO}_{2}$ insufflation enables very good identification of perforating veins and their safe clos.
3. The acquired experience allows intraoperative complications to be minimised.

4. SEPS/ESDP together with complementary methods is a recommendable way of lower leg chronic venous insufficiency treatment.

\section{References}

1. Negus D, Smith PD, Bergan JJ. Owrzodzenia podudzi - diagnostyka i leczenie. Alfa Medica Press, 2006; 9-19.

2. O'Donnell TF. The present status of surgery of the superficial venous system in the management of venous ulcer and the evidence for the role of perforator interruption. J Vasc Surg 2008; 48: 1044-52.

3. O'Donnel TF. Lessons from the past guide the future: is history traly circular? J Vasc Surg 1999; 30: 776-86.

4. Jugeheimer M, Nagel K, Junginger Th. Ergebnisse der endoscopischen Perforans-Dissection. Chirurg 1991; 62: 625-8.

5. Wente MN, Seiler CM, Uhl W, Buchler MW. Perspectives of evidence-based surgery. Dig Surg 2003; 20: 263-9.

6. Guyatt G, Schumenmand H, Cook D, et al. Grades of recommendation for antithrombotic agents. Chest 2001; 119: 35-75.

7. Biland L, Widmer LK. Varicose veins (VV) and chronic venous insufficiency (CVI). Medical and socio-economic aspects, Basle study. Acta Chir Scand Suppl 1988; 544: 9-11.

8. Widmer LK, Zemp E, Maggs M. Varicose veins and chronic venous insufficiency - A disorder or disease? A critical epidemiological rewiew. Vasa 1986; 15: 126-34.

9. Ciostek P. Endoskopowe podpowięziowe przecinanie żył przeszywających goleni. Biblioteka Polskiego Przeglądu Chirurgicznego 1999; 11: 3

10. Hach W, Gruß JD, Hach-Wunderle V, Jünger M. Chirurgia żył. 2009; 1: 19-21.

11. Linton RR. The postthrombotic ulcer of the lower extermity: its etiology and surgical treatment. Ann Surg 1953; 138: 416-23.

12. Cockett FB, Jones BE. The ankle blow-out syndrome. Lancet 1953; 1: $17-23$.

13. Dodd H, Cockett FB. The pathology and surgery of the veins of the lower limbs. T2. Churchill Livingstone. London 1976.

14. Stuart WP, Adam DJ, Allan PL, et al. Saphenous surgery does not correct perforator incompetence in the presence of deep venous reflux. J Vasc Surg 1998; 28: 834-8.

15. Markel A, Manzo RA, Berglin RO, et al. Incidence and time of occurrence of valvular incompetence following deep vein thrombosis. Wien Med Wochenschr 1994; 144: 216-20.

16. Johnson BF, Manzo RA, Bergelin RO, et al. Relationship between changes in the deep venous system and the development of the postthrombotic syndrom after an acute episode of lower limb deep vein thrombosis: a one-to six-year follow-up. J Vasc Surg 1995; 21: 307-13.

17. Kistner RL. Proceedings: post-phlebitic syndrome: cure by surgical repair of the incompetent femoral value. J Cardiovasc Surg 1976; 17: 85-6.

18. Almogren B, Eriksson I, Bylund H, et al. Phlebographic evaluation of nonthrombotic deep venous incompetence: new anatomic and functional aspects. J Vasc Surg 1990; 11: 389-96. 
19. Christopoulos D, Nicolaides AN, Cook A, et al. Pathogenosis of venous ulcer in relation to the calf muscle pump function. Surgery 1989; 106: 829-35.

20. Delis KT, Husmann M, Kalodiki E, et al. In situ hemodynamics of perforating veins in chronic venous insufficiency. J Vasc Surg 2001; 33: 773-82.

21. Eliska O, Eliskova M. Morphology of lymphatics in human venous crural ulcers with lipodermatoclerosis. Lymphology 2001; 34: 111-23.

22. Nicolaides AN. Investigation of chronic venous innsufficiency: a consensus statement. Circulation 2000; 102: e126-63.

23. Lim RC, Blaisdell FW, Zubrin J, et al. Subfascial ligation of perforating veins in recurrent stasis ulcer. Am J Surg 1970; 119: 246-9.

24. Hauer $G$. The endoscopic subfascial division of the perforating veins - preliminary report. VASA 1985; 14: 59-61.

25. O'Donnell TF. Surgical treatment of incompetent perforating veins. In: Atlas of venous surgery. Bergan JJ, Kistner RL (ed.). Philadelphia, Saunders 1992.

26. O’Donnell TF. Laparoscopic venous surgery in current critical problems in vascular surgery. Vol. 4. Veith FJ. Quality Medical Publishing 1992.

27. Ciostek P, Górski G, Noszczyk W. Development of the subfascial endoscopic perforator vein surgery (SEPS) and its influence on the final postoperative results. Vasc Surg 1998; 32: 151-6.

28. Gloviczki P, Cambria RA, Rhee RY, et al. Sugical technique and preliminary results of endocopic subfacial division of perforating veins. J Vasc Surg 1996; 23: 517-23.

29. Conrad P. Endoscopic exploration of the subfascial space of the lower leg with perforator vein interruption using laparoscopic equipment: a preliminary report. Phlebology 1994; 9: 154-7.

30. Pesta W, Wirkowski A, Wójcik S. Technique of cruroscopy with ESDP. Videosurgery and Other Miniinvasive Techniques 2007; 2 (suppl. 1): 10-5.

31. Kostewicz W, Ciostek P, Noszczyk W. A new method utilizing subfascial $\mathrm{CO}_{2}$ insufflation and videotechnique in postthrombotic syndrome endoscopic surgery. Surg Endosc 1994; 8: 53-5.

32. Kuś D, Juźwiak W, Goliszewski J, Stryga W. Subfascial endoscopic perforator vein surgery. Videochirurgia 1997; 2: 55-8.

33. Modrzejewski A, Śledź M, Halczak M, Hamera T. Endoscopic technique for the treatment of venous ulceration. Videochirurgia 2003; 3-4: 51-2

34. Dancewicz M, Sapieżko J, Brocki M. Treatment of chronic venous insufficiency with the usage of SEPS - early results. Videochirurgia 2000; 2: 11, A 306.

35. Sosada K, Żurawiński W, Martula M. Assessment of the results of postthrombotic syndrom treated with videocruroscopy. Videochirurgia 1997; 1: 41, P18.

36. Baler PM, Daopulos A. Miszczak ZT, König N. Indikationen, Ergebnisse und Erfahrungen mit der endoskopisch subfaszialen Perforantendissektion (ESPD). Eine prospektive Studie. Gefässchirurgie 2007; 12: 33-42.

37. Mozes G, Gloviczki P, Menawat SS, et al. Surgical anatomy for endoscopic subfascial division of perforating veins. J Vasc Surg 1996; 24: 800-8.

38. Mayer T, Cavallaro A, Lang W. Duplex ultrasonography in the diagnosis of incompetent Cockett veins. Eur J Ultrasound 2000; 11: $175-80$.
39. Bengisun U, Tagil SM, Elhan A. Accessibility of calf perforating veins from the superficial posterior compartment: an anatomic dissection study. Eur J Endovasc Surg 2003; 25: 522-55.

40. TenBrook JA, Lafrati MD, O'Donnell TF, et al. Systematic rewiew of outcomes after surgical managment of venous disease incorporating subfascial endoscopic perforator surgery. J Vasc Surg 2004; 39: 583-9.

41. Stacey MC, Bumand KG, Layer GT, et al. Calf pump function in patients with healed venous ulcers is not improved by surgery to the communicating veins or by elastic stocking. Br J Surg 1988; 75: 436-9.

42. Zamboni P, Cisno C, Marchetti F, et al. Minimally invasive surgical managment of primary venous ulcers vs. compression treatment: a randomized clinical trial. Eur J Vasc Endovasc Surg 2003; 25: 313-8.

43. Van Gent WB, Hop WC, van Pragg MC, et al. Conservative versus surgical treatment of venous leg ulcers: a prospective, randomized, multicenter trial. J Vasc Surg 2006; 44: 563-71.

44. Barwell JR, Davies CE, Deacon J, et al. Comparison of surgery and compression with compression alone in chronic venous ulcer (ESCHAR study): randomised controlled trial. Lancet 2004; 363: 1854-959.

45. Gloviczki P, Bergan JJ, Menawat SS, et al. Safety, feasibility, and early efficacy of subfascial endoscopic perforator surgery: a preliminary report from the North American registry. J Vasc Surg 1977; 25: 94-105.

46. Jugenheimer M, Junginger T. Endoscopic subfascial sectioning of incompetent perforating veins in the treatment of primary varicosis. World J Surg 1992; 16: 971-5.

47. Pierik EG, van Urk $\mathrm{H}$, Wittens $\mathrm{CH}$. Efficacy of subfascial endoscopy in eradicating perforating veins of the lowerand its relation with venous ulcer healing. J Vasc Surg 1997; 26: 255-9. 